$\xi=-1$

\title{
Design and performance evaluation through synchro-phasor signals for transient fault analysis in transmission lines and distributions
}

\author{
M. Nithyavelam ${ }^{1,2}$, Joseph Henry ${ }^{2}$ \\ ${ }^{1}$ Assistant Professor, Electronics \& Communication Engineering, Veltech University, Avadi \\ ${ }^{2}$ Professor, Electrical \& Electronics Engineering,Veltech University, Avadi \\ *Corresponding author E-mail: nithyavelam1987@gmail.com
}

\begin{abstract}
Contemporary power supplies be obliged to offer trustworthy, superior-quality power. Hence, it is significant to facilitate the transmission line fault identification more precise, consistent and to be rectified immediately. In this paper, a unique organized interrelated structure for identifying the transient fault that occurs in transmission lines and distribution is proposed, by employing the Fast Fourier Transform (FFT). This technique utilizes synchrophasor measurements during disturbances found in transmission lines positioned in the network and compared the obtained flux phase with the reference signal that is $230 \mathrm{~V}, 50 \mathrm{~Hz}$ flux phase which is considered as the ideal condition. The obtained difference phase angle will provide the details of transients present in the given transmission lines present between the generator and the load. By employing this method, the Initial state of transient fault detection from phasor measurement as well as a Linear Regression Modelling for Transient Fault Detection also be able to be identified. This paper analysis the transient fault using synchro-phasors by comparing the existing fault detection with real-time implemented system.
\end{abstract}

Keywords: Synchro-Phasors; Fast Fourier Transform (FFT); Linear Regression Modelling.

\section{Introduction}

Transmission lines and distributions are always subjected to faults. Protection systems, and following fault location methods are used to identify and isolate the least possible area that includes the faulted component and restore the normal operating condition. In this way, precise fault location is essential to progress the system trustworthiness by sinking the outage and service restoration time [1], [2].Conventional methods use amply independent information which will be inexact during faults. To be sure, transmission lines may lose their accuracy or, in some cases, their ability to properly transduce post-fault signals for a transient period consequent to the fault inception [1]. However, conventional approaches articulate the problem centered on the quantities calculated at the faulted line ends, which are also the closest ones to the fault. In this respect, wide-area fault location is a feasible substitute that affords the opportunity of utilizing highly reliable measurements, but they are not close to the fault [4]-[20].

The identification of a location of transmission line fault in a power grid is of great importance to facilitate self-healing of the system and for maintaining the reliability of power supply [21]. Further, the continuous power systems expansion and a load of varying nature have imposed high requirements in protecting equipment, mainly related with speed and accuracy. These are important factors for fault clearance. If a fault is not properly detected and removed, widespread damage or a power system blackout may take place [22].

The behavior of protective devices may change with the various types of loads such as linear and non-linear loads connected with the distribution system [23]. The transmission line protection schemes are divided into three stages: (i) fault detection and classification, (ii) fault zone estimation or fault location and (iii) decision logic and subsidiary modules [24]. Therefore, the detection of faults is an essential part of the protection scheme. The various techniques for detection of transmission line faults have been proposed in the literature. Krishnan and et al. [25], represented a pattern recognition method for current differential relaying of transmission lines and distribution. This method is projected for the differential current protection for a transmission line that nurtured from both the ends for a variation of faults, fault resistance, inception angles and also significant noise that present in the signal with the help of computer simulation studies. There are numerous conservative approaches for prediction of these faults such as Zbus matrix technique. No doubt there are circuit breakers and relays which come in the category of switchgear but the major and transient faults will not be rectified. The most significant parameter that varies and has to be controlled when the fault occurs is the fault current. The numerous mathematical manual approaches for estimation of fault current such as Bus impedance matrix, $\mathrm{Z}$ busmatrix etc.

These techniques are considered as complicated for solving complex networks of transmission lines and distribution and as well as for maintaining the parameters of transmission lines that are not constant and calculations transforms problematic as the length of the network upsurges the calculation, that becomes additional complex. Also fault classification and detection are done by using various practices that are advanced and will be highly precise by means of various software such as Matlab, PSCAD, and EMTDC. This method includes adaptive fault protection scheme for transmission lines using synchronized phasor measurements in this paper it has been discussed the various techniques for fault classi- 
fication, location, and detection. The remaining part of the paper is projected as follows. Section 2 explains the proposed transient fault-location method. The performance of the proposed algorithm is analyzed under Section 3. Section 4 describes the result and discussion. Section 5 concludes the paper.

\section{Methodology}

The block diagram of the proposed method is given in figure 1 . In this method, Data acquisition (DAQ) with a computer is utilized in order to measure the electrical phenomenon such as voltage and current. When comparing with the existing measurement systems, Computer-based DAQ systems becomes first by having less processing power, large productivity, Foremost quality display, and connectivity capabilities for industry-standard PC's given that a supplementary dominant, supple, and cost-effective measurement elucidation. With the help of DAQ B-Class Amplifier, it is possible to take the electrical signals directly from the distributed transmission lines. The cardinal fragments of the DAQ structure are DAQ measurement hardware, and then the computer that has the programmable software. In order to arrest the noise signals from the transmission lines, a Signal Conditioning circuitry present in the DAQ will employ the acquired signals in a form that is suitable for input to an Analog-to-Digital Converter (ADC). The DAQ will also execute amplification, attenuation, filtering, and isolation.

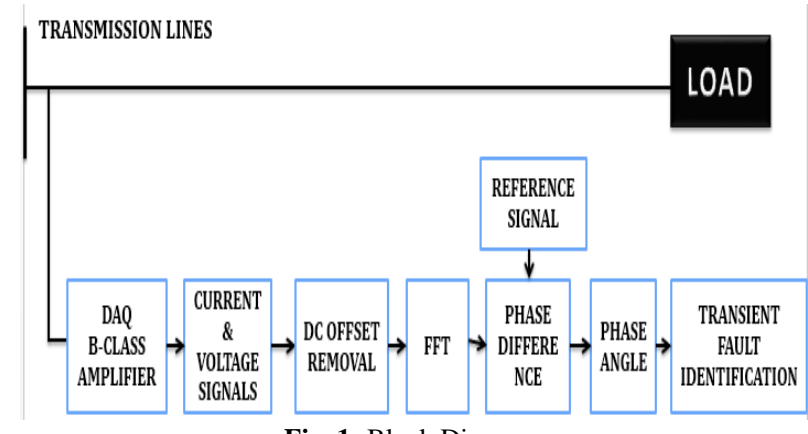

Fig. 1: Block Diagram.

Thus the obtained analog signals from distributed transmission lines then convert into digital after that the system will do the execution process. At the essential time, we will get the digital illustration of the attained analog signal with the assistance of the Analog-to-Digital Converter. In a pre-defined rate, the Analog-toDigital converter gets periodic "samples" of the signal from the continuous analog signal which constantly vary with time. These samples are moved to a computer, in which the novel signal is erected again from the samples.

Although the digitized current and voltage signals gained from the DAQ amplifier comprises of DC offset, therefore it is necessary to remove completely to get the correct output. DC offset is a fault that suddenly happens in the current and voltage signals directly obtained from Transmission lines, which is nothing but the sine wave suddenly becomes asymmetrical, and after a few cycles returns to normal (symmetrical). This fault will be reflected in the digitized current and voltage signals obtained from the DAQ amplifier. DC offset removal block removes the DC offset present in the digitized current and voltage signals obtained from DAQ. The DC offset error is shown in figure 2 .

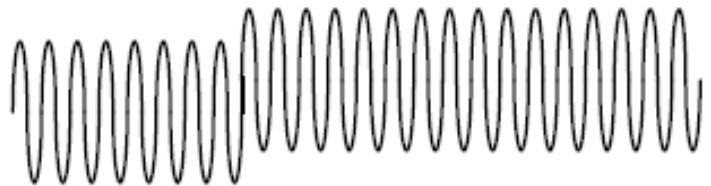

Fig. 2: Offset Error.
Due to the miscarriage of rectifier which converts Alternating current(AC) to Direct current (DC), there is the possibility of Direct Current that could be induced into an $\mathrm{AC}$ distribution system, that have flourished modern equipment. DC has the possibility to crisscross the AC power system and add annoying current to devices that are previously functioning at their assessed rating level. Circulating DC current produces overheating and saturation of transformers. Due to saturation, the transformer becomes hot and also incapable of delivering full power to the load, and the succeeding waveform distortion can generate auxiliary unsteadiness in electronic load equipment. A DC offset is shown in Figure.

The solution to DC offset complications is to interchange the faulty equipment that is the source of the Problem. Since highly modular, user-friendly, apparatus can significantly raise the easiness to solve DC offset problems produced due to faulty equipment, with fewer costs than may usually be needed for dedicated healing labor. After removal of DC offset, the obtained digitized signals are subjected to an efficient algorithm named Fast Fourier Transform (FFT). Thus the phase of the obtained current and voltage signals can be calculated precisely with the help of the FFT. Now the phase of the ideal signal and the transmission lines having transient faults are observed. By comparing the two signals it is possible to obtain the flux phase difference and its angle using the Fast Fourier Transform algorithm. By repeating the experiments using different types of transients it is possible to obtain the average flux phase difference between the ideal signal and transient faults.

\section{a) Transient Fault}

If repeated flipping of switch occurs, then the inductors and capacitors present in the transmission lines require a transitory time for getting charges because since that moment they had reacted steadily with the alternating current.

A transient fault is a fault that is no longer present if power is disconnected for a short time and then restored or an insulation fault which only affects transmission line's dielectric properties temporarily that will be restored after a short interval of time. Many faults in overhead power lines are transient in nature. When a fault occurs, equipment used for power system protection operate to isolate the area of the fault. A transient fault will then clear and the power-line can be returned to service. Typical examples of transient faults include:

- momentary tree contact

- bird or other animal contact

- lightning strike

- conductor clashing

Transmission and distribution systems use automatic reclose function which is frequently used on $\mathrm{OH}$ lines in order to restore power in the incident of a transient fault. This functionality is not as common on underground systems as faults there are typical of a determined environment. Transient faults will cause loss both at the location of the original fault or somewhere else in the network, as fault current is generated. Transients are significant, as any power system need to be fortified to overcome peaks and also other tiny duration things in addition to the steady state power. In transmission lines, transient faults occur due to lightning strikes and switching transients that will propagate down the line and finally reach the substation. 


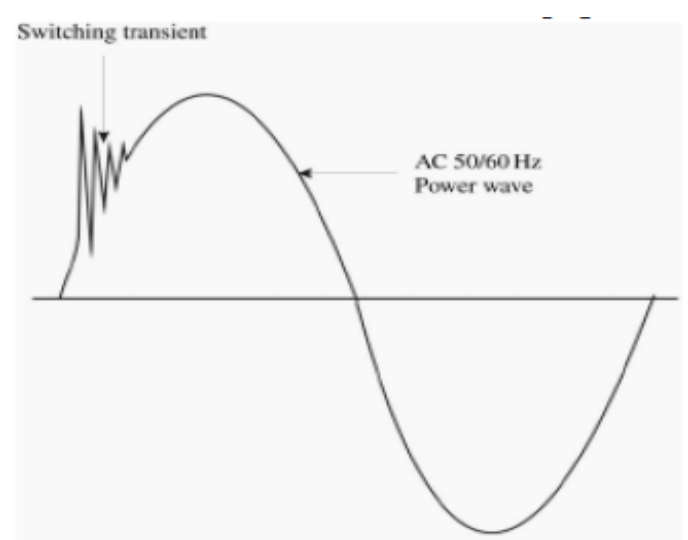

Fig. 3: Switching Transient Fault Present in 50/60Hz Transmission Line.

In the substation, the voltage will be clamped with the help of lightning arresters to a threshold level such that the substation equipment can handle without damage. Figure 3 shows the Switching transient fault present in a $50 / 60 \mathrm{~Hz}$ transmission line. Shunt capacitors play an important role in power system transmission lines and distribution systems as the means of delivering reactive power. The main benefits of utilizing shunt capacitors are, they are cost efficient and its suppleness in the case of installation and operation. These capacitors are employed in the Power system, to control system voltage and to escalate power transfer ability, to decrease equipment loading, and to diminish energy costs by improving the power factor of the transmission lines.

Though, during energizing the shunt capacitors, a transient oscillation develops in the power systems. Because of this fact, the operation of switching shunt capacitors happens repeatedly, shunt capacitor switching is observed as the central source of producing transient voltages on numerous utility systems. This type of transient faults can cause harms on both utility systems and customer systems, based on the power system parameters such as transformer size, and the type of customer loads that is connected to the system.

Overhead $(\mathrm{OH})$ Transmission circuits are habitually High Voltage level $(110 \mathrm{kV}$ or $115 \mathrm{kV}$ and more) to Extra High Voltage levels (230kV and beyond) and Ultra High Voltage levels $(765 \mathrm{kV}$ and beyond). Overhead Head Distribution schemes comprise subtransmission system circuits like $66 \mathrm{kV}$ down to $11 \mathrm{kV}$ and also there is a possibility of as low as $3.3 \mathrm{kV}$.

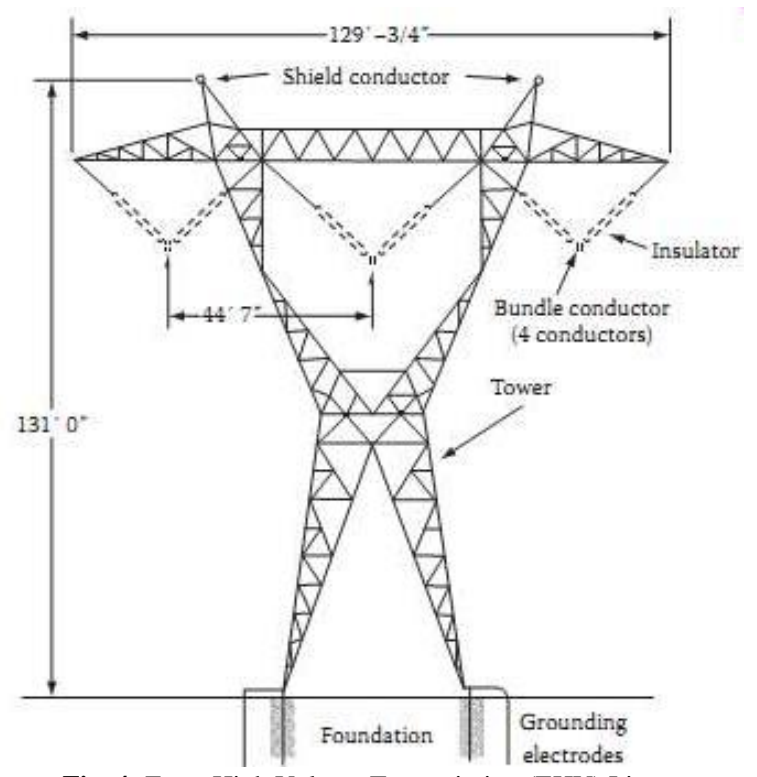

Fig. 4: Extra High Voltage Transmission (EHV) Lines.

EHV Lines (Fig.4) are tall constructions and has insulators that have higher creepage distances as well as clearances. Faults occurrence in $\mathrm{OH}$ lines of these levels is rare. Occasional faults occur between phases that involve three phases. Common faults are one phase to ground faults that are generally because of flashover present across insulator due to certain surges. Basic Insulation Levels (BIL) are very greater than lightning surge and therefore are conducted away by surge arresters thus creating switching surges as foremost cause of flashovers. However, flashover across insulator on lightning are not unusual in areas of developed keraunic levels. The keraunic level defines the lightning and thunder action in a given area.

It is demarcated as the annual number of days, the thunder can be heard. This number in particular areas will vary a lot, and the keraunic level is the long-term average. In temperate regions the keraunic level lies from 10 to 30; in the African rainforest area, the keraunic levels will exceed 180 . The annual number of lightning flashes hitting one square $\mathrm{km}$ of ground, $\mathrm{N}_{\mathrm{g}}$, for temperate regions are calculated using the formula

$\mathrm{N}_{\mathrm{g}}=0.04 \mathrm{~T}_{\mathrm{d}}^{1.25}$

Where $T_{d}$ is the keraunic level.

Practically, $T_{d}$ is used to create standards for the safe scheme of electrical systems in structures associated to the local power grid.

The lower end of Extra High Voltage level circuits will also get faults often $(220 \mathrm{kV}, 230 \mathrm{kV})$ that are referred as transient faults. Few $380 \mathrm{kV}, 400 \mathrm{kV}$ systems that are present in heavy thunderstorm areas will also get transient faults.

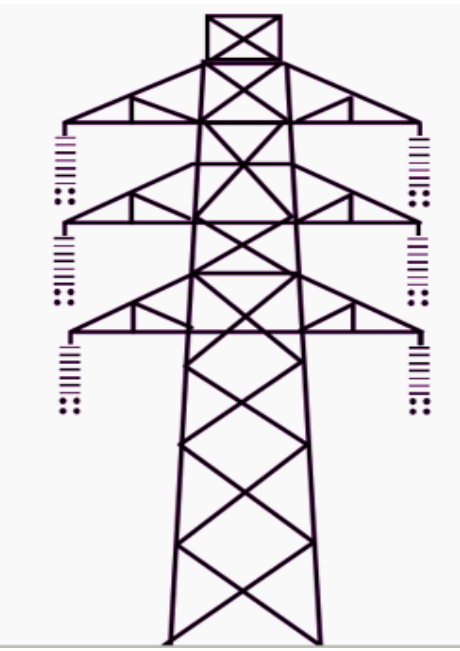

Fig. 5: High-Voltage Transmission Lines (HV OH Lines).

$\mathrm{HV} \mathrm{OH}$ lines (figure 5) transmission lines are not as tall as Extra High Voltage Overhead Transmission lines and the occurrence of transient faults are very common. In Middle Eastern countries, filthy insulators, salty atmosphere creates large numbers of transient faults during heavy fog or during light rain drops. Some transient faults will also occur if filthy insulators are washed with hot water.
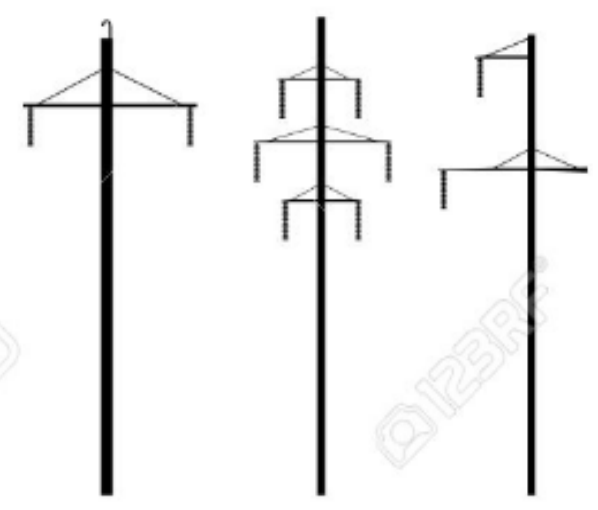

Fig. 6: Overhead Distribution Lines. 
Overhead Transmission Lines (figure 6) are usually applied in rural feeders and it will frequently get most kinds of faults because of its nearness to load centers. Transient faults are mostly common.

b) Synchro-phasor

A sinusoidal signal can be represented by a cosine function with a magnitude A, frequency $\omega$, and phase $\varphi$. A is the RMS value of the voltage/current signal.
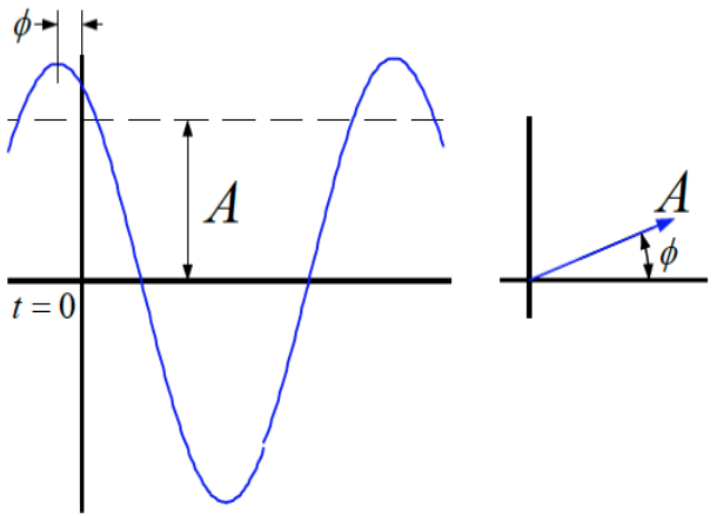

Fig. 7: Phasor Representation of Sinusoidal Waveform.

$x(t)=\sqrt{2} A \cos (2 \pi 60 t+\varphi)$

A synchrophasor is a phasor measurement with respect to an entire time reference. The phasor representation of the sinusoidal waveform is shown in figure 7. Using this synchro-phasor it is possible to conclude the absolute phase relationship amongst phase quantities at diverse locations on the power system. Figure 8 shows the phasor representation of $\mathrm{AC}$ waveform.

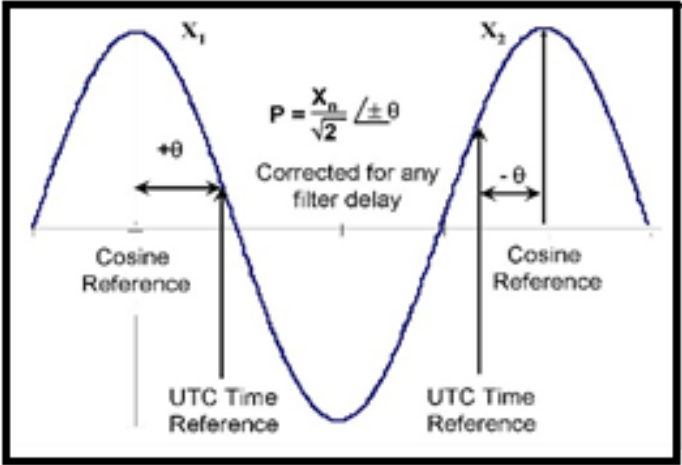

Fig. 8: Phasor Representation of AC Waveform.

Using the synchrophasor measurement, the adjacent bus voltage phasors at the same time instants, the P, Q flow can be computed.

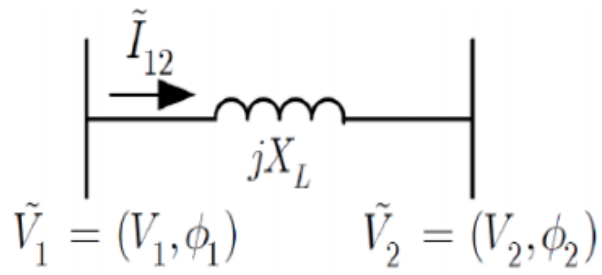

Fig. 9: Computation of Phase Angle from Synchro-Phasors.

The two voltage phasors can be measured at precisely the same time. The computation of phase angle from synchrophasor is shown in figure.9.

$$
\tilde{I}_{12}=\frac{\tilde{V}_{1}-\tilde{V}_{2}}{j X_{L}}, \quad S_{12}=\tilde{V}_{1} \bullet \tilde{I}_{12}{ }^{*}=P_{12}+j Q_{12}, \quad P_{12}=\frac{V_{1} V_{2} \sin \left(\phi_{1}-\phi_{2}\right)}{X_{L}}
$$

By noticing the angle separation between the generator and the load, buses provide a reliable way to assess system stress conditions. The angle separation is shown in figure 10

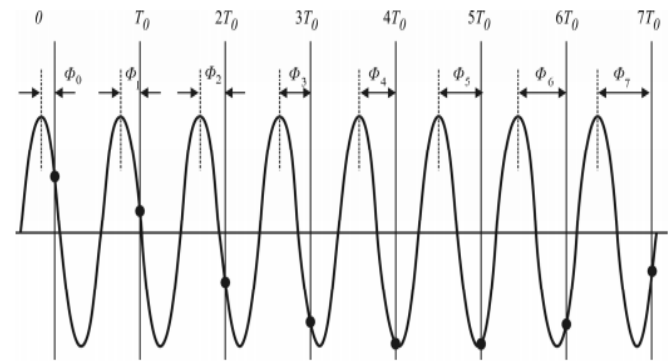

Fig. 10: A Sinusoid with A Frequency $F>F_{0}$ Is Observed at Instants that are $\mathrm{T}_{0}$ Seconds Apart. The Phase Angle $\Phi$ Increases Uniformly in Relation to the Frequency Difference, $\mathrm{F}-\mathrm{F}_{0}$.

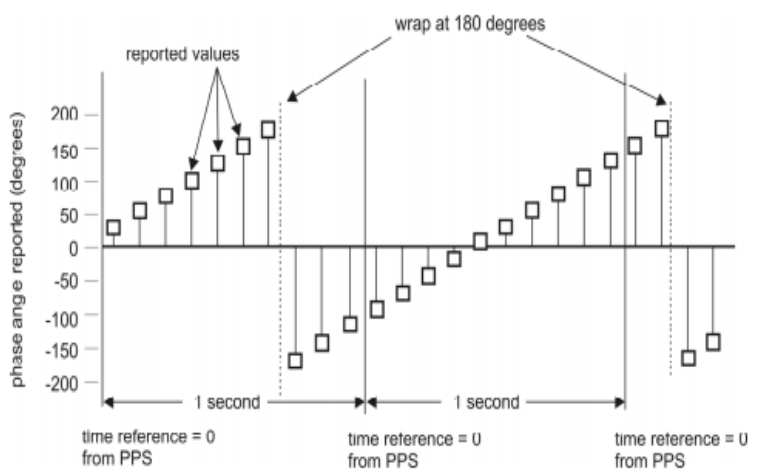

Fig. 11: Sampling a Power Frequency Sinusoid at Off-Nominal Frequency.

Differences in the actual frequency are comprised in the phase angle estimation. The sampling of the sinusoidal signal is shown in figure 11. The synchrophasor evaluation also comprises the effects of all other signal contributions such as oscillations and also local frequency swings. Synchro-phasors are functions of time and can change from one value to the next until unless the signal is a pure sinusoid at a nominal system frequency. A precise time reference (clock) is required to provide the UTC time to determine the phase angle $\varphi$.

\section{Results and discussion}

As demonstrated, the proposed method is realized as follows. In the experimental set-up, the load was connected at the end of $10 \mathrm{~m}$ of transmission cable and the signal from transmission cable reaches the load in 60 seconds. The transient fault is created at the position of $17^{\text {th }} \mathrm{sec}$ by switching off the power. The phasor is measured for both ideal and transient condition for fault identification. The figure 12.a shows the ideal condition and the figure $12 . \mathrm{b}$ shows the signal at the transient condition.

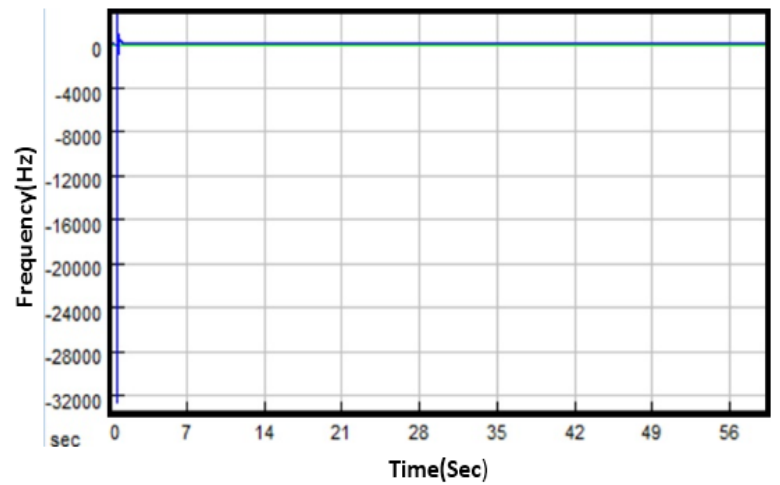

Fig. 12: (A) Ideal Signal. 


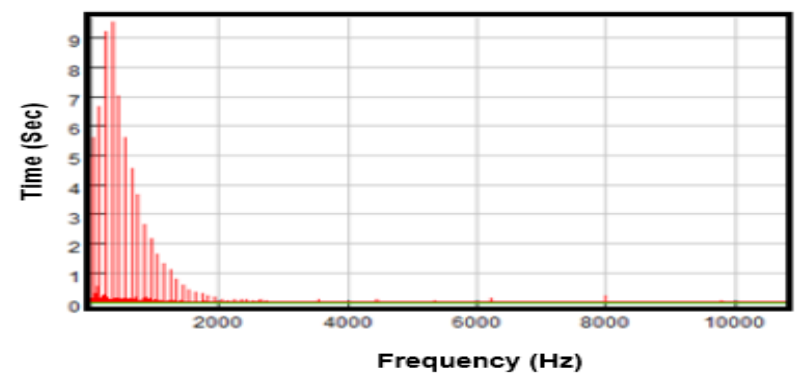

Fig. 13: (A) FFT Plot for Ideal Transmission Lines.

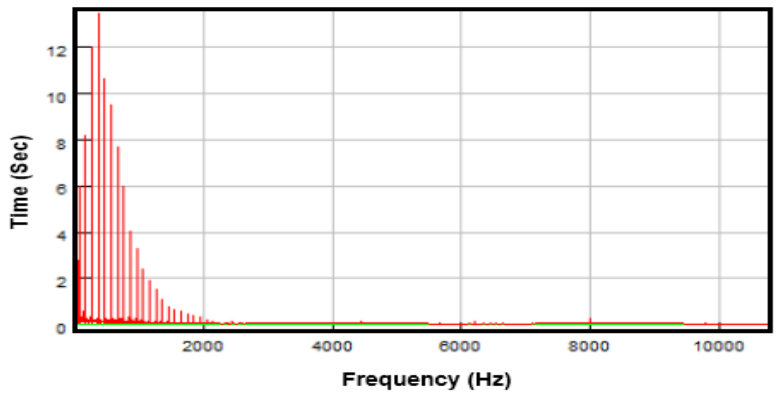

Fig. 13: (B) FFT Plot for Transmission Lines Having Single Transient Fault.

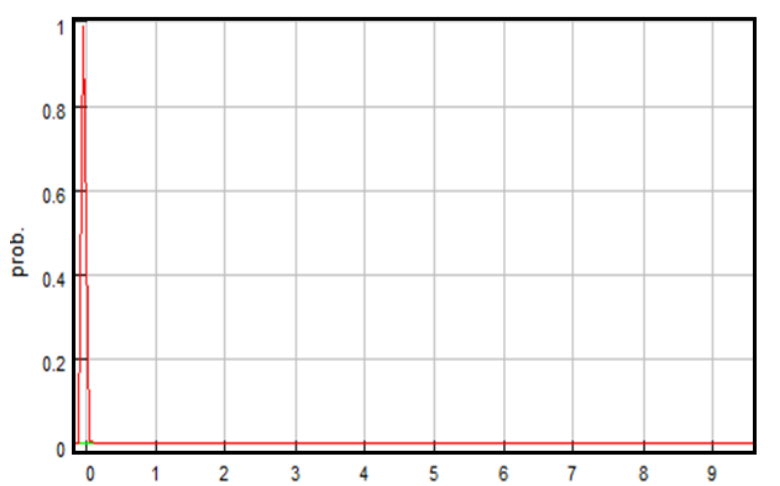

Fig. 14: (A) Probability Distribution Curve for Ideal Transmission Lines.

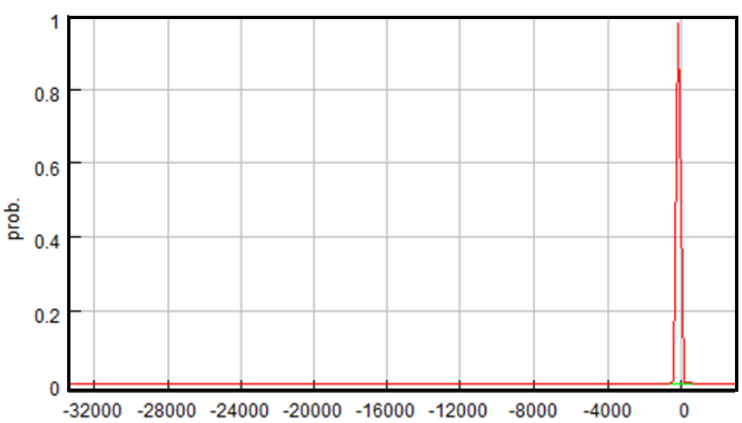

Fig. 14: (B) Probability Distribution Curve for Transmission Lines Having Induced Single Transient Fault.

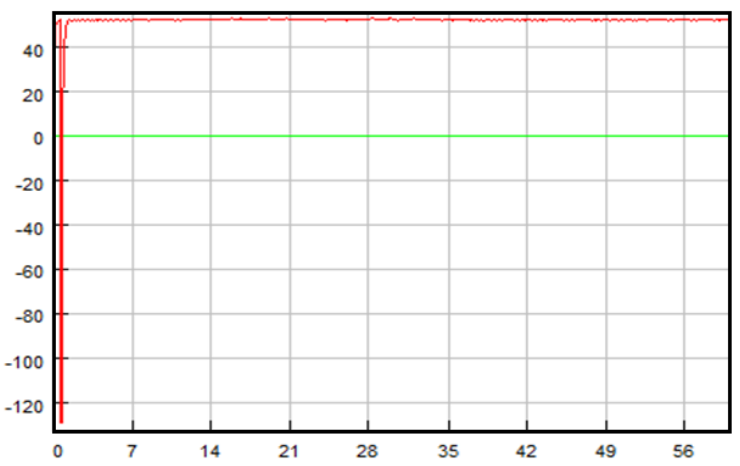

Fig. 15: (A) Integral Curve for Ideal Transmission Lines.

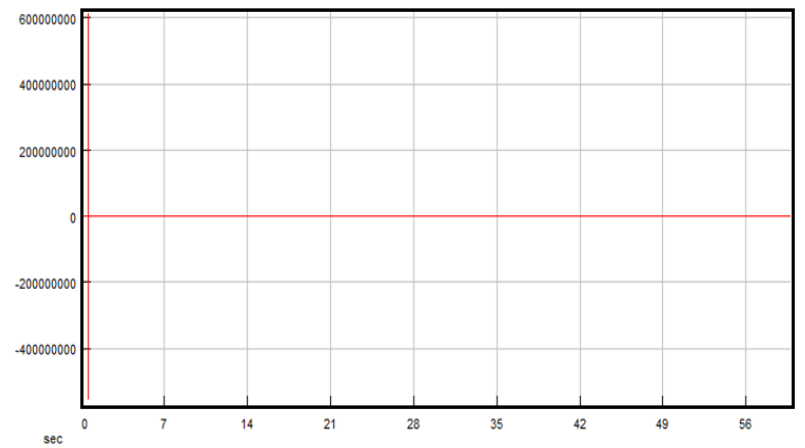

Fig. 15: (B) Integral Curve for Transmission Lines Having Induced Single Transient Fault.

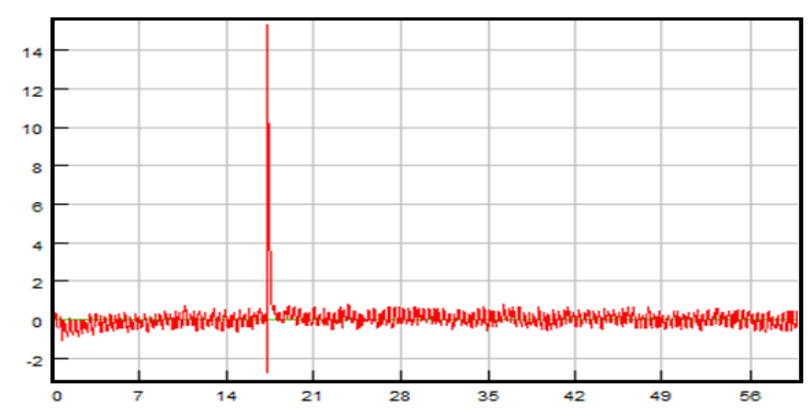

Fig. 16: (A) Differentiation Curve for Ideal Transmission Lines.

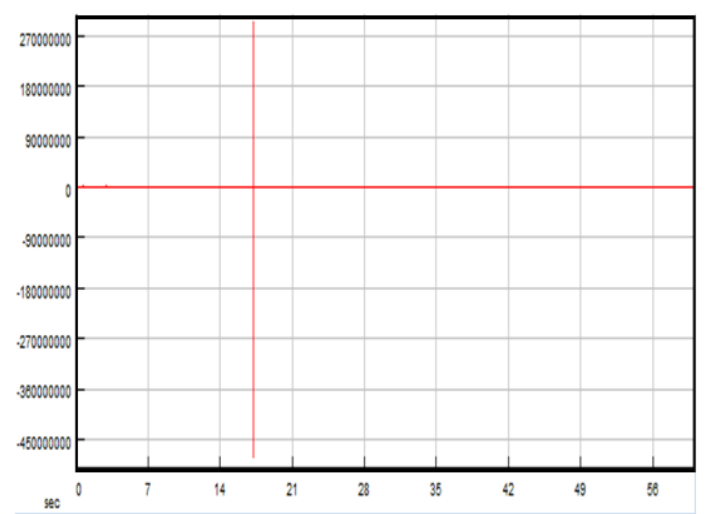

Fig. 16: (B) Differentiation Curve for Transmission Lines Having Induced Single Transient Fault.

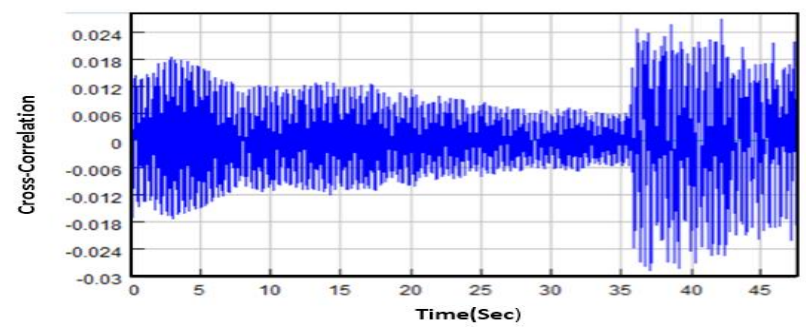

Fig. 17: (A) Cross-Correlation Between Ideal Transmission Line and Induced Single Transient Fault Is Calculated As 5.

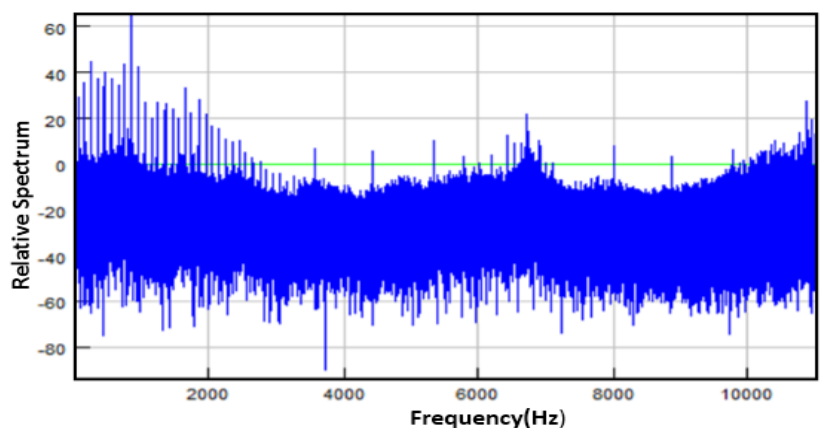

Fig. 17: (B) Relative Spectrum between Ideal Transmission Line and Induced Single Transient Fault Is Calculated As 12. 
The FFT plot for the ideal transmission lines and the induced single transient fault within 60sec is shown in figure 13(a) and 13(b). The probability distribution curve for the ideal transmission lines and the induced single transient fault within 60sec is shown in figure 14(a) and 14(b). The integral curve for the ideal transmission lines and the induced single transient fault within $60 \mathrm{sec}$ is shown in figure 15(a) and 15(b). The differential curve for the ideal transmission lines and the induced single transient fault within 60sec is shown in figure 16(a) and 16(b). Cross-correlation and the relative spectrum between the ideal signal and the induced single transient fault have also been calculated and shown in figure 17 (a) and 17(b).

The flux phase difference between different types of faults are tabulated as follows:

Table 1: Results of Fault Location Technique Using Phase Difference between the Signals

\begin{tabular}{llll}
\hline $\begin{array}{l}\text { Type of } \\
\text { fault }\end{array}$ & $\begin{array}{l}\text { Fault Transi- } \\
\text { ents }\end{array}$ & $\begin{array}{l}\text { Calculated faulty flux } \\
\text { difference }\end{array}$ & $\begin{array}{l}\text { Percentage } \\
\text { Error }\end{array}$ \\
& Within 60 & & \\
\hline & sec. & -83.99 & 76.66944 \\
& 1 & -86.289 & 76.03083 \\
& 3 & -88.221 & 75.49417 \\
Transient & 9 & -89.220 & 75.21667 \\
Fault & 12 & -90.325 & 74.90972 \\
& 18 & -90.156 & 74.95667 \\
& 21 & -91.568 & 74.56444 \\
& 24 & -91.447 & 74.59806 \\
& 27 & -92.241 & 74.3775 \\
& 30 & -93.77 & 73.95278 \\
\hline
\end{tabular}

The transient fault is created in the transmission lines prototype with the minimum of 1 transients per $60 \mathrm{sec}$ to the maximum threshold of 30 transients per sec. From the table I it is clear that when the transient rate is as 1 per 2 seconds, then the percentage error is reduced. This shows that the transient fault will be clearly identified when there is minimum transients occurs. When the flux phase difference between the ideal signal which is $230 \mathrm{~V}, 50 \mathrm{~Hz}$ signal, and the signal consists of transient faults is varied between -83.99 to -93.77 . The presence of transient fault will create approximately $75.893 \%$ error in the transmission lines.

This could be tested for every 1-kilometer distance from the transmission lines distributor to the load. If at any point the flux phase difference between the transmission lines distribution and the actual flux present in the lines are between 81deg to 94deg then the fault present in the particular location is identified as a transient fault and the value of flux phase difference will provide the intensity of transients present in the given transmission lines. Once the obtained fault is decided as a transient fault with the help of the flux phase difference then it is necessary to locate the position as well as eradication is also a vital progress in the development of error-free transmission lines. It is achieved by obtaining the detailed characteristics of the fault present in the transmission lines. Thus the complete characteristics of 1 transient per second are given with the comparison of an ideal signal is given in table II. The characteristics of the given induced single transient signal resemble the ideal signal up to 16.99 seconds after that from 17th second the characteristics of the signal starts vary that resembles that the fault is initiated at the 17th second from the transmission line while it is traveling to the load. The output is shown in figure 18. The intensity of the fault will be measured using the obtained characteristics that are shown in table II.

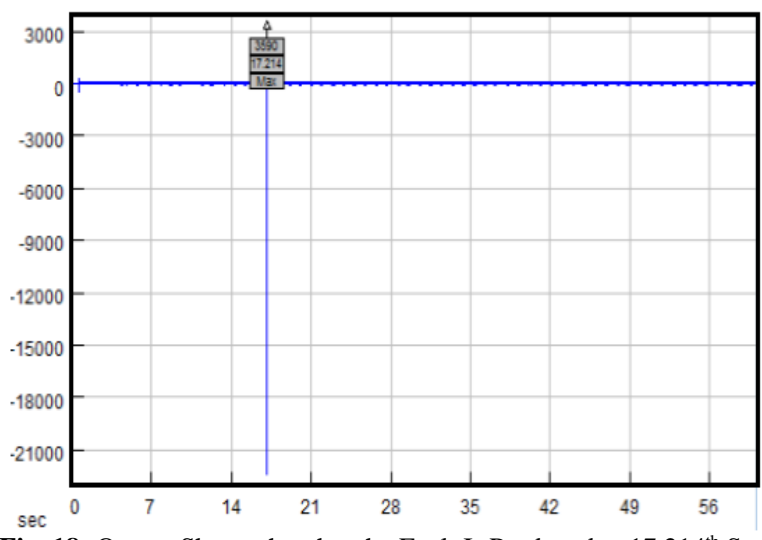

Fig. 18: Output Shows that that the Fault Is Produced at $17.214^{\text {th }}$ Sec.

\begin{tabular}{lll}
\multicolumn{2}{c}{ Table 2: } \\
\hline \multirow{2}{*}{ Signal Parameters } & $\begin{array}{l}\text { Ideal Signal } \\
(230 \mathrm{v}, 50 \mathrm{hz})\end{array}$ & $\begin{array}{l}\text { Signal With 1 Transient Per } \\
60 \text { Seconds }\end{array}$ \\
\hline SNR & $37.636 \mathrm{db}$ & $27.0288 \mathrm{db}$ \\
Mean & 0.869734 & 0.000401 \\
Crest factor & 228.618 & 623.378 \\
Variance & 20541.6 & 1304.72 \\
Skewness & -48.8447 & -209.662 \\
Kurtosis & 10349.2 & 15188 \\
Normalized RMS & 143.324 & 36.121 \\
THD & $7.06142 \%$ & $17.4361 \%$ \\
Weighted Mean & $5($ at $20.182 \mathrm{sec})$ & $39(\mathrm{at} 30.012 \mathrm{sec})$ \\
Zero-crossing rate & 1050.69 & 976.795 \\
\hline
\end{tabular}

\section{Conclusion}

The emerging route in transmission line's quality monitoring lies in real-time detection and management. Researchers have paid supplementary consideration on researching detection and management of Transmission lines quality. This article remarks a method for finding transient faults in transmission lines based on fast Fourier transformation. It can be active on de-noise, the recognition of disturbance's start time, amplitude, and frequency. A widely suitable, low-cost, as well as an exact procedure for transmission-line checking was estimated and established in this paper. This technique takes the ideal signal as the reference and compared it with the induced transient faults present in the transmission lines. It is tested for various cases and finally comes to a conclusion that if the flux phase difference is nearly $83 \%$ to $93 \%$ then the error present in transmission lines are due to unexpected transients present in the transmission lines. The phase comparison is achieved with the help of fast Fourier transform. The DAQ BClass Amplifier utilized in this method makes this technique as achievable and practical. With the help of DC offset removal block, DC offset problem in more complicated situations with multiple transmission lines are solved successfully. As such, this witnessing skill has the excessive perspective to augment situational consciousness, authorize dynamic line evaluation, and understand advanced system measurement of the future smart grid.

\section{References}

[1] M. M. Saha, J. J. Izykowski, and E. Rosolowski, Fault Location on Power Networks, 1st ed. London, U.K.: Springer, 2010. https://doi.org/10.1007/978-1-84882-886-5.

[2] IEEE Guide for Determining Fault Location on AC Transmission and Distribution Lines, IEEE Std. C37.114-2004, 2005.

[3] Mahamdedi, M. Sanaye-Pasand, S. Azizi, and J. G. Zhu, "Unsynchronised fault location technique for three-terminal lines," IET Gen., Transm., Distrib., vol. 9, no. 15, pp. 2099-2107, Jun. 2015.

[4] M. R. Jegarluei, A. S. Dobakhshari, A. M. Ranjbar, and A. Tayebi, "A new algorithm for fault location on transmission lines by optimal PMU placement," Int. Trans. Elect. Energy Syst., Jul. 2014.

[5] K. P. Lien, C. W. Liu, C. S. Yu, and J. A. Jiang, "Transmission network fault location observability with minimal PMU place- 
ment," IEEE Trans. Power Del., vol. 21, no. 3, pp. 1128-1136, Jul. 2006. https://doi.org/10.1109/TPWRD.2005.858806.

[6] J. Zare, F. Aminifar, and M. Sanaye-Pasand, "Synchrophasor-based wide-area backup protection scheme with data requirement analysis," IEEE Trans. Smart Grid, vol. 30, no. 3, pp. 1410-1419, Mar. 2015. https://doi.org/10.1109/TPWRD.2014.2377202.

[7] M. Kezunovic and Y. Liao, "Fault location estimation based on matching the simulated and recorded waveforms using genetic algorithms," in Proc. Int. Conf. Develop. Power Syst. Protect., RAI, Amsterdam, the Netherlands, Apr. 2001. https://doi.org/10.1049/cp:20010184.

[8] A. S. Dobakhshari and A. M. Ranjbar, "A circuit approach to fault diagnosis in power systems by the wide-area measurement system," Int. Trans. Elect. Energy Syst., vol. 23, no. 8, pp. 1272-1288, Nov. 2013. https://doi.org/10.1002/etep.1654.

[9] Z. Galijasevic and A. Abur, "Fault location using voltage measurements," IEEE Trans. Power Del., vol. 17, no. 2, pp. 441-445, Apr. 2002. https://doi.org/10.1109/61.997915.

[10] A. S. Dobakhshari and A. M. Ranjbar, "Application of synchronized phasor measurements to wide-area fault diagnosis and location," IET Gen., Transm., Distrib., vol. 8, no. 4, pp. 716-729, Apr. 2014.

[11] Y. Liao, "Fault location for single-circuit line based on bus impedance matrix utilizing voltage measurements," IEEE Trans. Power Del., vol. 23, no. 2, pp. 609-617, Apr. 2008. https://doi.org/10.1109/TPWRD.2008.915799.

[12] N. Kang and Y. Liao, "Double-circuit transmission line fault location with the availability of limited voltage measurements," IEEE Trans. Power Del., vol. 27, no. 1, pp. 325-336, Jan. 2012. https://doi.org/10.1109/TPWRD.2011.2168547.

[13] N. Kang and Y. Liao, "Double-circuit transmission line fault location utilizing synchronized current phasors," IEEE Trans. Power Del., vol. 28, no. 2, pp. 1040-1047, Apr. 2013. https://doi.org/10.1109/TPWRD.2013.2246587.

[14] Q. Jiang, X. Li, B. Wang, and H. Wang, "PMU-based fault location using voltage measurements in large transmission networks," IEEE Trans. Power Del., vol. 27, no. 3, pp. 1644-1652, Jul. 2012 https://doi.org/10.1109/TPWRD.2012.2199525.

[15] S. Azizi and M. Sanaye-Pasand, "A straightforward method for wide area fault location on transmission networks," IEEE Trans. Power Del., vol. 30, no. 1, pp. 441-445, Feb. 2015. https://doi.org/10.1109/TPWRD.2014.2334471.

[16] A. S. Dobakhshari and A. M. Ranjbar, "A novel method for fault location of transmission lines by wide-area voltage measurements considering measurement errors," IEEE Trans. Smart Grid, vol. 6, no. 2, pp. 874-884, Mar. 2015 https://doi.org/10.1109/TSG.2014.2322977.

[17] G. Feng and A. Abur, "Identification of faults using sparse optimization," in Proc. 52nd Annu. Allerton Conf. Communication, Control, and Computing, Sep. 30-Oct 3, 2014. https://doi.org/10.1109/ALLERTON.2014.7028569.

[18] S. Azizi, M. Sanaye-Pasand, M. Abedini, and A. Hassani, "A traveling wave-based methodology for wide-area fault location in multiterminal DC systems," IEEE Trans. Power Del., vol. 29, no. 6, pp. 2552-2560, Aug. 2014. https://doi.org/10.1109/TPWRD.2014.2323356.

[19] M. Korkali and A. Abur, "Optimal deployment of wide-area synchronized measurements for fault-location observability," IEEE Trans. Power Syst., vol. 28, no. 1, pp. 482-489, Feb. 2013. https://doi.org/10.1109/TPWRS.2012.2197228

[20] S. Azizi, S. Afsharnia, and M. Sanaye-Pasand, "Fault location on multiterminal DC systems using synchronized current measurements," Int. J. Elect. Power Energy Syst., vol. 63, pp. 779-786, Dec. 2014. https://doi.org/10.1016/j.ijepes.2014.06.040.

[21] Pathirikkat Gopakumar, Maddikara Jaya Bharata Reddy, and Dusmanta Kumar Mohanta, "Transmission line fault detection and localization methodology using PMU measurements," IET Generation, Transmission \& Distribution, Vol. 9, Iss. 11, pp. 1033-1042, 2015. https://doi.org/10.1049/iet-gtd.2014.0788.

[22] D. Guillen, M. Roberto, A. Paternina, A. Zamora, J. M. Ramirez, and G. Idarraga, "Detection and classification of faults in transmission lines 137 using the maximum wavelet singular value and Euclidean norm," IET Generation, Transmission \& Distribution, Vol. 9, No. 15, pp. 2294- 2302, 2015. https://doi.org/10.1049/ietgtd.2014.1064

[23] Moslem Dehghani, Mohammad Hassan Khooban, and Taher Niknam, "Fast fault detection and classification based on a combination of wavelet singular entropy theory and fuzzy logic in distribution lines in the presence of distributed generations," Internation- al Journal of Electrical Power and Energy Systems, vol. 78, pp. 455-462, 2016. https://doi.org/10.1016/j.ijepes.2015.11.048.

[24] A. A. Yusuff A. A. Jimoh J. L. Munda, "Determinant-based feature extraction for fault detection and classification for power transmission lines," IET Generation, Transmission \& Distribution, Vol. 5, Iss. 12, pp. 1259-1267, 2011.

[25] K. R. Krishnan and, P. K. Dash, and M. H. Naeem, "Electrical Power and Energy Systems Detection, classification, and location of faults in power transmission lines," International Journal of Electrical Power and Energy Systems, Vol. 67, pp. 76-86, 2015. https://doi.org/10.1016/j.ijepes.2014.11.012. 